\title{
Optimal integration of mobile battery energy storage in distribution system with renewables
}

\author{
Yu ZHENG ${ }^{1}$, Zhaoyang DONG ${ }^{2}$, Shilin HUANG $^{3}$, Ke MENG ${ }^{2}$, \\ Fengji LUO ${ }^{1}$, Jie HUANG ${ }^{4}$, David HILL ${ }^{2,5}$
}

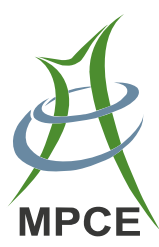

\begin{abstract}
An optimal sizing method is proposed in this paper for mobile battery energy storage system (MBESS) in the distribution system with renewables. The optimization is formulated as a bi-objective problem, considering the reliability improvement and energy transaction saving, simultaneously. To evaluate the reliability of distribution system with MBESS and intermittent generation sources, a new framework is proposed, which is based on zone partition and identification of circuit minimal tie sets. Both
\end{abstract}

CrossCheck date: 4 February 2015

Received: 1 September 2014 / Accepted: 2 February 2015/Published online: 22 August 2015

(C) The Author(s) 2015. This article is published with open access at Springerlink.com

$\triangle$ Zhaoyang DONG

zydong@ieee.org

Yu ZHENG

zhy9639@hotmail.com

Ke MENG

funnyjason@gmail.com

Fengji LUO

fengji.luo@newcastle.edu.au

Jie HUANG

huangjie1@sgepri.sgcc.com.cn

David HILL

dhill@eee.hku.hk

1 Center for Intelligent Electricity Networks (CIEN), The University of Newcastle, Newcastle, NSW, Australia

2 School of Electrical \& Information Engineering, The University of Sydney, Sydney, NSW, Australia

3 Ningde Amperex Technology Ltd., Ningde, Fujian, China

4 State Grid Electric Power Research Institute, Nanjing, China

5 Department of Electrical and Electronic Engineering, The University of Hong Kong, Hong Kong, China analytic and simulation methods for reliability assessment are presented and compared in the framework. Case studies on a modified IEEE benchmark system have verified the performance of the proposed approach.

Keywords Mobile battery energy storage system (MBESS), Reliability, Markov models, Monte Carlo simulation

\section{Introduction}

Since 2009, a series of smart grid programs have been launched successively in the USA, EU, China, Japan, etc. [1]. Governments are placing enormous pressure on the energy industry to deploy smart grids. There have been noteworthy researches underway in formulating visions and promoting the development of smart grid $[2,3]$. One common element of these visions is seamless integration of advanced energy storage system to shape peak demand, to mitigate renewable fluctuation, to improve system reliability, and to defer infrastructure investment.

The advances in material science and power electronics technologies have facilitated the employment of advanced battery energy storage systems (BESS), which can quickly response to demand fluctuation. The development of BESS will be critical to effective levelling of the cyclic nature of peak demand and to defer the costly infrastructure investment. Moreover, mobility is required in some regions with seasonal demand, which means BESS could be transported to different regions in different seasons to meet increased demand [4]. Mobile battery energy storage system (MBESS) provides mobile and highly flexible storage capacity, and can be deployed at different parts of the network to ensure efficiency. Moreover, MBESS equipped with black-start function can provide buffering function action until the other 
distributed generations (DGs) are started in a controlled fashion and help the disconnected system back into operation. Along with the increasing penetration level of renewable energy, distribution system power flow is significantly altered in terms of direction and magnitude. It makes the existing issues, delivering reliable power, become even more challenging. With high performance MBESS solution, the adoption of renewable energy resources is expected to be accelerated. Therefore, another outstanding benefit of MBESS is reliability enhancement, which enables distribution system with fast self-healing capability. Therefore, distribution systems are well positioned to benefit from MBESS for maintaining reliability and power quality.

In order to integrate MBESS in distribution system optimally, a novel reliability evaluation method should be proposed, where islanded operation is allowed due to the integration of MBESS. There have been noteworthy researches in developing reliability assessment methods [5-9]. However, the modern DGs and BESS in distribution system can either affect system reliability due to intermittency or guarantee the uninterruptible power supply by operating as microgrid when fault occurs. The reliability evaluation of modern distribution system is different as the traditional ones. Besides the considerations of uncertainties [10], different DGs should be modelled in order to assess the system reliability. In [11], the impacts of wind energy and ESS on system reliability were evaluated. In [12], a multi-state model was proposed. Probabilistic models were used in adequacy calculation in [13]. The reliability of distribution system with multiple overhead feeders on a same tower was evaluated in [14].

In this paper, an optimal sizing method is proposed for MBESS in distribution network with renewables. The main
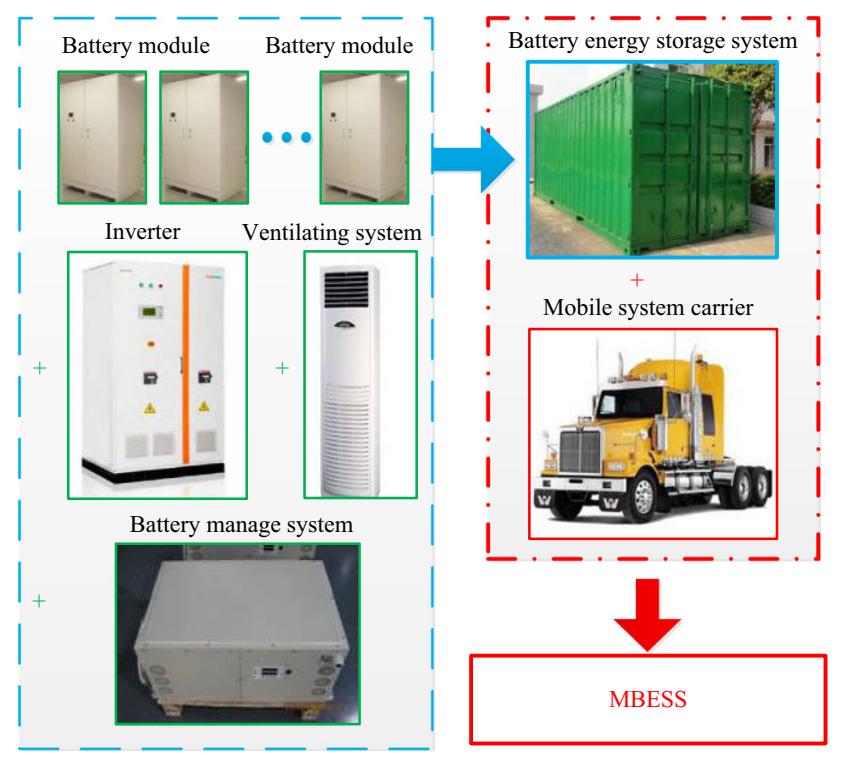

Fig. 1 MBESS configuration configuration of MBESS is showed in Fig. 1. A new framework is proposed to evaluate the reliability of distribution system with MBESS and DGs. Both analytic and simulation methods are presented and compared in the proposed framework. Factorization and decomposition are used to address the topology simplification [9]. Based on distribution system models, minimal cut-set technique [6, 9] and Markov models [15-17] are applied to evaluate simple systems, while the Monte Carlo simulation method can be performed for complex systems [18, 19]. Besides the reliability index, the economic performance is another key issue. Our previous work has demonstrated the economic feasibility of BESS project in different electricity markets $[20,21]$. The optimization results are applied in this paper to quantify the profit of MBESS during normal operation state. Therefore, the MBESS optimal capacity determination is formulated as a bi-objective problem, considering reliability improvement and energy transaction saving, simultaneously.

This paper is organized as follows, after introduction section; an optimal operation method for MBESS is presented. Then, an analytic reliability assessment method for small system is proposed. And the Monte Carlo simulation is presented and discussed for complicated system. After that, the optimal sizing method is performed based on reliability evaluation and economic results acquired in [20]. Finally, the proposed methods are verified on a modified IEEE 15-bus distribution network and an extended complicated system. Conclusions and further developments are discussed in the last section.

\section{Model development for reliability evaluation}

\subsection{Operation model of MBESS}

The latest material technology offers the lithium-based battery with higher power, faster charging/discharging rates, longer life cycles, and superior power to weight ratio when compared with the traditional lead-acid battery systems. Therefore, in this paper, the lithium-based MBESS will be investigated, which is used for emergency power supply and island operation support. In case of contingencies, after the fault area is isolated, MBESS will move to the downstream section, supplying buffering until the other DGs restarted in a controlled fashion to serve demand. The recovery time and the capacity of MBESS are the major factors for reliability improvement. The recovery time is affected by moving speed and distance in (1). The parameters of the investigated MBESS are listed in Table 1.

$t_{\text {up_MBESS }}=t_{\text {mov }}+t_{\text {install }}=k_{\text {traff }} \frac{D}{s_{\text {MBESS }}}+t_{\text {install }}$ 
Table 1 Typical parameters of mobile battery energy storage systems

\begin{tabular}{ll}
\hline Item & Lithium-ion battery \\
\hline Energy density $(\mathrm{Wh} / \mathrm{kg})$ & 250 \\
Power density $(\mathrm{W} / \mathrm{kg})$ & 500 \\
Life cycle (times) & 1500 \\
Investment $(\$)$ & $300 E_{r}$ \\
Energy efficiency & $85 \%$ \\
Moving speed $S_{\text {MBESS }}(\mathrm{km} / \mathrm{hr})$ & 20 \\
\hline
\end{tabular}

where $t_{\text {island }}$ is the time duration of island operation mode (hours); $t_{u p \_M B E S S}$ is start-up time of MBESS after fault (hours); $t_{\text {mov }}, t_{\text {install }}$ are moving time and installation time of MBESS (hours) respectively; and $k_{\text {traff }}$ is traffic situation factor.

The operation of MBESS can be described as

$\Delta E(t)=\int_{t}^{t+\Delta t}\left[P^{D i s / C h r}(t)-\eta_{c}\left|P^{D i s / C h r}(t)\right|\right] \mathrm{d} t$

where $E$ is energy stored in MBESS (MWh); $P^{D i s / C h r}$ is charging/discharging reference for MBESS (MW); $\eta_{c}$ is charging loss (\%); and $\Delta t$ is time interval (hours).

The state-of-charge (SOC) is expressed as

$\operatorname{SOC}(t)=\frac{E(t)}{E_{r}}$

where $E$ is energy stored in MBESS (MWh), and $E_{r}$ is rated energy capability of MBESS(MWh).

And the operation of MBESS is constrained to:

Power limits: $\quad P^{D i s, \text { Max }} \leq P^{D i s / C h r}(t) \leq P^{C h r, \text { Max }}$

SOC limits: $S O C^{\mathrm{Min}} \leq S O C(t) \leq S O C^{\mathrm{Max}}$

where $P^{D i s, \max }, P^{C h r, \max }$ are maximum discharging/charging power limits of MBESS (MW) respectively; and $S O C^{\mathrm{Max}}$, $S O C^{\text {Min }}$ are maximum and minimum state-of-charge of MBESS (\%) respectively.

\subsection{Distributed generation}

Wind power, one of the most appealing renewable energy sources, has been widely deployed in recent years. As wind speed increases, the power generated by turbine will increase correspondingly. Ignoring minor nonlinearities, the function relation between a given wind speed and power output can be described in (6).

$P_{\text {Wind }}= \begin{cases}0, & v<v_{\text {in }} \text { or } v>v_{\text {out }} \\ a V+b, & v_{\text {in }} \leq v \leq v_{r} \\ P_{\text {rated }}, & v_{r} \leq v \leq v_{\text {out }}\end{cases}$ where $a=\frac{w_{r}}{v_{r}-v_{i n}}, b=-\frac{v_{i n} w_{r}}{v_{r}-v_{i n}} ; P_{\text {Wind }}, P_{\text {rated }}$ are real power and rated power of wind generation (MW) respectively; $v_{i n}$, $v_{\text {rated }}, v_{\text {out }}$ are cut-in, rated, and cut-out speeds of wind turbine $(\mathrm{m} / \mathrm{s})$ respectively; and $v$ is real-time wind speed $(\mathrm{m} / \mathrm{s})$.

\subsection{Section model for distribution systems}

The establishment of section model for distribution system is the basic techniques to assess the system states. The section model is formed according to the location of switching devices [6, 14]. The following assumptions should be made.

1) The operation mode of distribution network is radial.

2) All the switches are reliable.

3) The failures rate is low.

4) There are no simultaneous failures.

Based on the above assumptions, the equivalent failure rate and failure outage duration of this section can be calculated by statistic data of internal component. The expressions are shown as (7) and (8).

$\lambda_{i}=\sum_{j \in i} \lambda_{j}$

$r_{i}=\sum_{j \in i} \frac{\left(\lambda_{j} r_{j}\right)}{\lambda_{i}}$

where $i$ is section number; $j$ is component number; and $\lambda$ is failure rate.

\section{Reliability assessment with MBESS}

As discussed above, the integration of MBESS in radial distribution system facilitates the operation of isolated section after fault and thereby increases the reliability. The Fig. 2 depicts the timetable of the section state of distribution system with and without MBESS. In island mode, the section locates at the downstream of fault area is isolated from the grid and powered by DGs and MBESS. The state of the island depends on the total amount of DG output and MBESS capability.

\subsection{Analytical assessment of distribution system reliability}

The analytical reliability evaluation methods are proposed for simple distribution system. The expected energy not supplied (EENS) can be improved with MBESS integration. The state space for the system is performed through Markov process model. A two-section distribution 


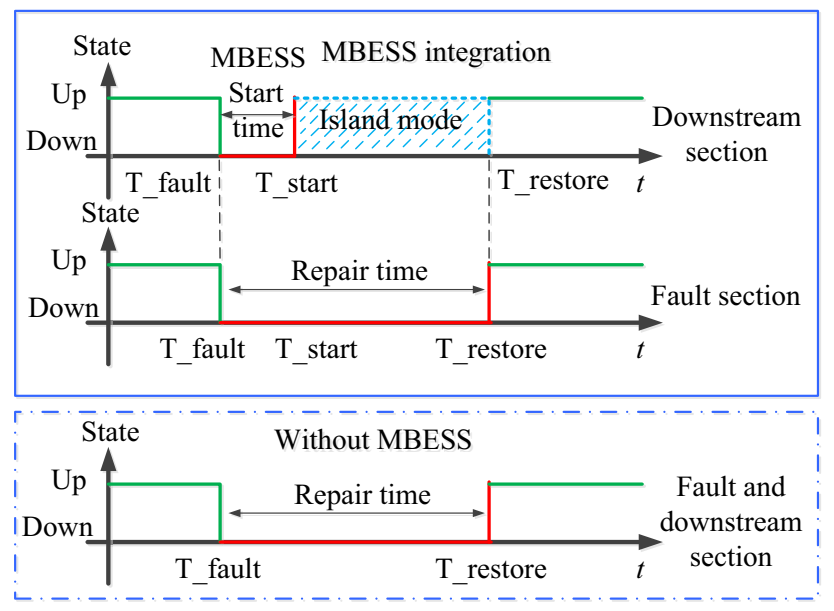

Fig. 2 State time table of distribution system with and without MBESS integration

system is used to explain the proposed reliability evaluation method. The system schematic and corresponding Markov process is expressed in Fig. 3. $\lambda_{1}$ is the failure rate of unit $1 ; \lambda_{2}$ is the failure rate of unit $2 ; \mu_{1}$ is the unit repair rate after battery installation; $\mu_{2}$ is the unit repair rate; Ins is the battery installation rate. Battery is "stand" as backup when there is no fault or the fault occurs outside the response area.

The equation for solving the probability of each state is shown as

$$
\left[\begin{array}{llll}
-\lambda_{1}-\lambda_{2} & \mu_{2} & 0 & \mu_{1} \\
\lambda_{2} & -\mu_{2} & 0 & 0 \\
\lambda_{1} & 0 & -r & 0 \\
0 & 0 & r & -\mu_{1}
\end{array}\right]\left[\begin{array}{l}
p_{1} \\
p_{2} \\
p_{3} \\
p_{4}
\end{array}\right]=0
$$

$p_{1}+p_{2}+p_{3}+p_{4}=1$

where $r$ is the outage duration.

It should be note that $\mu_{1}$ is the reciprocal of the mean time to repair after the installation of MBESS and $r$ is the reciprocal of the mean time to install. We assume that the mean time to repair is same for different sections. Hence, $\mu_{1}$ can be calculated by (10). Based on the state probability matrix, we can assess the system reliability by using EENS.

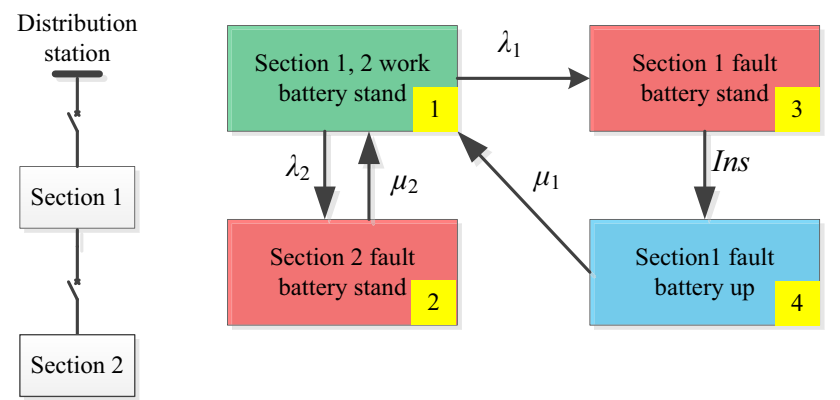

Fig. 3 Two section system and Markov state space
$\mu_{1}=\frac{1}{\frac{1}{\mu_{2}}-\frac{1}{\operatorname{Ins}}}$

In state 4 , section 2 is operating in island mode with MBESS. If the power output of MBESS can compensate the gap between demand and DG output, the island mode is feasible. The operation probability is expressed as

$p_{\text {island }}=\left.p\left(P_{\text {MBESS }}+P_{D G} \geq P_{\text {Load }}\right)\right|_{t=0} ^{t_{\text {island }}}$

where $P$ is the possibility of state; $P_{L o a d}, P_{D G}$ are demand, distributed generation output (MW) respectively; and $p_{i s l a n d}$ is the success rate of island operation mode.

Historical data based statistics method is applied to determine the success probability of island operation mode. Renewable energy output and demand data are collected to perform the operation process of concerned section. The success rate from any fault time is calculated respectively. During each operation time horizon $t_{\text {island }}$, time interval is set to 1 hour. If the constraint $P_{i}^{D i s}(t)+P_{D G, i}(t) \geq L_{i}(t)$ is satisfied for time $t$, the success flag is set to 1 , as $s_{i}^{i s l a n d}(t)=1$. Let $p_{i, t_{0}}$ denotes the success probability of island operation mode during fault event $t_{0}$.

$p_{i, t_{0}}=\int_{t=t_{0}}^{t_{0}+t_{\text {isand }}} s_{i}^{\text {island }}(t) \mathrm{d} t / t_{\text {island }}$

where $t_{\text {island }}$ is the fault duration. Suppose $N_{\text {sample }}$ is the simulation times, the average ratio incan be calculated as

$p_{i}=\sum_{t_{0}=1}^{N_{\text {sample }}} p_{i, t_{0}} / N_{\text {sample }}$

According to the definition, the EENS index is calculated as (14).

$$
\begin{aligned}
\text { EENS }= & \left\{p_{2} \cdot \overline{L(2)}+p_{3} \cdot[\overline{L(1)}+\overline{L(2)}]\right\} \cdot 8760 \\
& +p_{4} \cdot\left[\overline{L(1)}+\overline{L(2)} \cdot\left(1-p_{\text {island }}\right)\right] \cdot 8760
\end{aligned}
$$

\subsection{Time-sequential Monte Carlo simulation}

Since the state space of the system is difficult to be determined, to evaluate the reliability of a complex system, a Monte Carlo simulation method is desired to present the fault and system operation states precisely. A two-level Monte Carlo simulation for system state is proposed. At first level, the fault section is determined. In this paper, we assume that no fault occurs in the system simultaneously. The failure rate of the section is acquired by (7) and (8). The system state parameter $R$ is generated randomly from the uniform distribution. Then, the fault location is determined according to the following criterion,

$$
i_{\text {fault }}=\{\operatorname{Ceil}(\operatorname{Rand}() *(k+1))\}
$$


where $k$ is the total number of sectors in the concerned system; ceil () the function to round the element to the nearest integer greater than or equal to that element.

If fault location is $k+1$, no fault occurs at first level, the second level simulation is skipped. Otherwise, the island state is determined in the second level. In this level, the downstream tree from fault section is searched for the target island area and the MBESS is sent to support the island operation. After the moving and installation time of MBESS, the demand and renewable energy output is sampled from the time-varying model until the fault line is repaired. During the MBESS operation time, if the sampling renewable output and MBESS output can meet the sampling demand, the islanding operation mode is succussed. Otherwise, both the demand and renewable energy are out of service.

In this sampling simulation, the fault is far less than generated sample times. Therefore, bootstrapping method is applied to improve the calculation time [22]. The scaling sample method and the reliability objective function are expressed as

$$
\left\{\begin{array}{l}
r^{\prime}=N_{\text {boost }} \cdot r \\
\text { EENS }=\frac{E E N S^{\prime}}{N_{\text {boost }}}
\end{array}\right.
$$

$F_{1}\left(E_{r}\right)=\operatorname{EENS}(0)-\operatorname{EENS}\left(E_{r}\right)$

where $F_{1}$ is the EENS improvement function with MBESS integration.

\section{Economic evaluations and sizing problem}

The optimal allocation method of BESS is proposed in [21], the economic feasibility is verified through the novel operation strategy. In this work, during the normal operation state, MBESS is controlled by the DisCo at the substation site to make profit. Similar to the previous work, the location of BESS is set at the substation and the economic can be expressed as

$F_{2}=J\left(E_{r}\right)$

where $J$ is the cost function. The detailed operation strategy and market environment are described in [20].

Two objectives, reliability improvement and energy transaction saving, are quantified as a function of capacity. The optimal sizing issue can be formulated as a bi-objective problem. Since these two objectives are measured in different unit, in order to optimize the sizing of MBESS comprehensively, membership function, proved to be a good solution to the multi-objective problem, is used to fuzzify the objective function [23].
$\vartheta_{x}=\frac{\left|F_{x}\left(E_{r}\right)-F_{x}^{\text {best }}\right|}{\left|F_{x}^{\text {worst }}-F_{x}^{\text {best }}\right|} \quad$ for $x=1,2 ;$

where $F_{x}^{\text {best }}$ and $F_{x}^{\text {worst }}$ for $x=1,2$ are the best and worst values of the two objectives; and $\vartheta_{x}$ are the weight factors. Through the normalization process, the overall fuzzy multiobjective function of the MBESS sizing problem is expressed as

$\min F\left(E_{r}\right)=\vartheta_{1} F_{1}\left(E_{r}\right)+\vartheta_{2} F_{2}\left(E_{r}\right)$

\section{Case study}

A modified IEEE $11 \mathrm{kV}, 15$-bus distribution radial system is used to verify the proposed reliability evaluation method for distribution system with MBESS. The one-line diagram of this distribution system is shown in Fig. 4. The reliability parameters for the lines are list in Table 2.

1) Analytic reliability assessment

Firstly, according to the section concept, the reliability data for the lines are converted for the section. The results are shown in Table 3. The system is assumed as a residential system, the average load index is 0.59 while the average wind farm output index is 0.3. Then, the Markov state space is constructed as Fig. 5 and only two typical capacities are selected for calculation in this part. The results are showed in Table 4. In the demonstration system, $\lambda_{1}, \lambda_{2}$, and $\lambda_{3}$ are the failure rates of the three sections, respectively; $\mu_{1}$ and $\mu_{2}$ are the unit repair rate after battery installation, $\mu_{3}$ is the unit repair rate; Ins is the battery installation rate.

From the reliability indices shown in Table 5, the EENS index is improved by $29.2 \%$ and $40.4 \%$ with the integration of $500 \mathrm{kWh}$ and $1 \mathrm{MWh}$ MBESS, respectively. Then, the

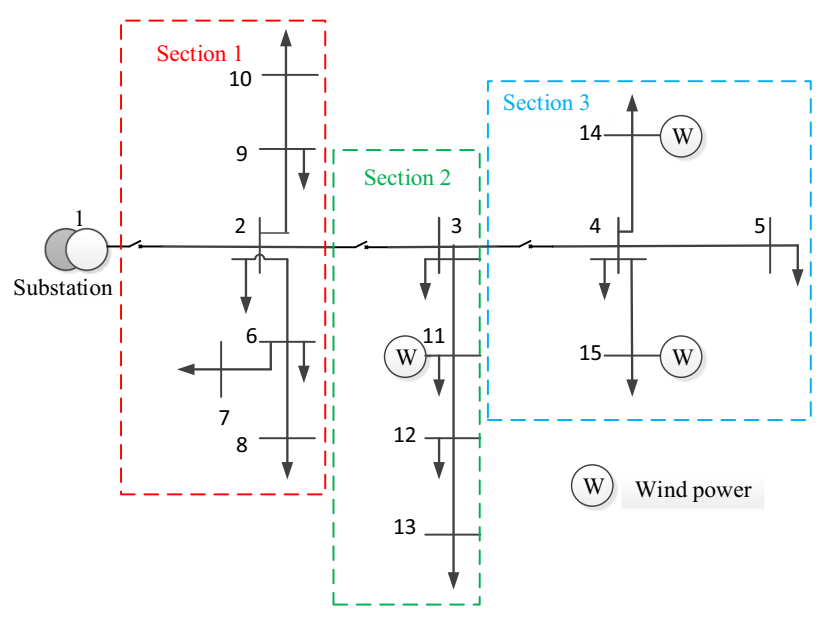

Fig. 4 Modified IEEE 15-bus distribution radial system 
Table 2 Reliability data for the distribution lines

\begin{tabular}{ll}
\hline Line & $\lambda(\mathrm{f} / \mathrm{y})$ \\
\hline $1-2$ & 0.054 \\
$2-3$ & 0.0468 \\
$3-4$ & 0.0336 \\
$4-5$ & 0.0988 \\
$2-9$ & 0.1308 \\
$9-10$ & 0.1096 \\
$2-6$ & 0.1662 \\
$6-7$ & 0.0707 \\
$6-8$ & 0.0813 \\
$3-11$ & 0.1167 \\
$11-12$ & 0.1591 \\
$12-13$ & 0.1308 \\
$4-14$ & 0.1450 \\
$4-15$ & 0.0778 \\
\hline
\end{tabular}

Table 3 Reliability data for the Section

\begin{tabular}{lllllll}
\hline Section & $\lambda(\mathrm{f} / \mathrm{y})$ & $r(\mathrm{hr})$ & $\mu$ & Ins & $\begin{array}{l}\text { Peak load } \\
(\mathrm{kW})\end{array}$ & $\begin{array}{l}\text { Renewable } \\
\text { energy }(\mathrm{kW})\end{array}$ \\
\hline 1 & 0.6126 & 5 & $\frac{8760}{5-0.234}$ & $\frac{8760}{0.17}$ & 508.2 & 0 \\
2 & 0.4534 & 5 & $\frac{8760}{5-0.293}$ & $\frac{8760}{0.234}$ & 324.1 & 750 \\
3 & 0.3552 & 5 & $\frac{8760}{5}$ & $\frac{8760}{0.293}$ & 464.1 & 500 \\
\hline
\end{tabular}

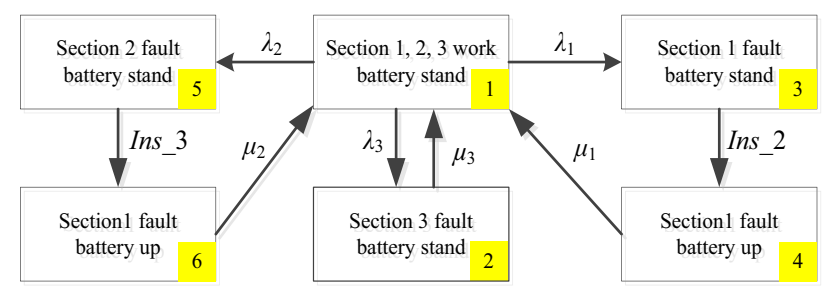

Fig. 5 Markov state space for 15 bus test system

Table 4 Reliability indices of the 15 bus test systems (analytic method)

\begin{tabular}{llcc}
\hline Section & Without MBESS & 500 kWh MBESS & 1 MWh MBESS \\
\hline 1 & 916.6767 & 916.6767 & 916.6767 \\
2 & 1016.773 & 581.6877 & 581.6877 \\
3 & 1942.91 & 811.6183 & 811.6183 \\
Syst & 3876.359 & 2309.983 & 2309.983 \\
\hline
\end{tabular}

Monte Carlo simulation are performed to verify the proposed analytic method.

2) Monte Carlo simulation assessment

A Monte Carlo simulation for reliability assessment is performed in this section. Artificial history of one year is generated in each simulation sample. The boost scaling
Table 5 Reliability indices of the 15 bus test systems (Monte Carlo simulation results)

\begin{tabular}{lcccc}
\hline Case & Section & $\begin{array}{l}\text { EENS }^{\prime} \\
(\mathrm{MWh})\end{array}$ & $\begin{array}{l}\text { EENS } \\
(\mathrm{kWh})\end{array}$ & $\begin{array}{l}\text { Renewable } \\
\text { Energy } \\
\text { Saving }(\mathrm{kWh})\end{array}$ \\
\hline $\begin{array}{l}\text { Without Renewable } \\
\text { Energy and MBESS }\end{array}$ & System & 37.2317 & 3723.17 & 0 \\
$\begin{array}{l}500 \mathrm{kWh} \text { MBESS } \\
1 \mathrm{MWh} \text { MBESS }\end{array}$ & System & 27.8059 & 2780.59 & 449.48 \\
\hline
\end{tabular}

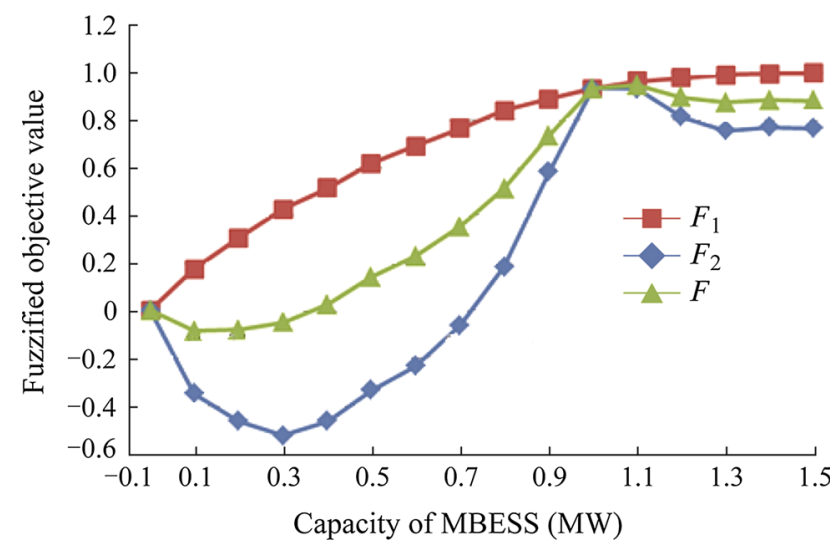

Fig. 6 Objective curves of the optimization problem

factor $N_{\text {boost }}$ is set to 10 and the sample time is 2000 . During the sampling process of island mode, the 24-hours and 4-seasons residential demand data is used in the demand sampling while the wind speed distributions are fitted for renewable energy output sampling. The simulation results are provided in Table 5.

From the result of Monte Carlo simulation, the EENS value with different size of MBESS integration is very close to the result of proposed analytic method. The differences are all within $4 \%$. Therefore, both the analytic and Monte Carlo simulation method can be applied for reliability assessment of distribution system with MBESS integration.

3) Optimal capacity determination

The above part demonstrates the integration of MBESS can improve the reliability of the distribution system and save the renewable energy during island operation periods. The quantified value is expressed by $\vartheta_{1} F_{1}\left(E_{r}\right)$. The economic index is indicated by $\vartheta_{2} F_{2}\left(E_{r}\right)$. Both the objectives are function of the energy capacity $E_{r}$. The optimization process can be realized by an enumeration method. The fuzzified objective curves are showed in Fig. 6 and the optimal capacity results are listed in Table 6. From the results, we can find that the optimal capacity is larger than the result without the reliability consideration in our previous work. 
Table 6 Optimization result

\begin{tabular}{lllll}
\hline $\begin{array}{l}\text { Capacity } \\
(\mathrm{MWh})\end{array}$ & $\begin{array}{l}\text { EENS improvement } \\
F_{1}(E)(\mathrm{MWh})\end{array}$ & $\vartheta_{1} F_{1}(E)$ & $\begin{array}{l}\text { Profit } \\
F_{2}(E)(\$)\end{array}$ & $\vartheta_{2} F_{2}(E)$ \\
\hline 1.1 & 1.0332 & 0.9646 & 1600 & 0.933 \\
\hline
\end{tabular}

\section{Conclusion}

This paper proposes a practical method for integrating MBESS in distribution system. Both analysis and simulation methods are proposed for the reliability evaluation of distribution system with the integration of MBESS and DGs, which can help the downstream section of the fault area back to operation as an island in a short time. In the case study, the analysis method achieves good results without complex calculation. The simulation method is applied to verify the accuracy of analysis method. Through this work, a reliability evaluation framework for the distribution system with MBESS is proposed and verified. The optimal MBESS capacity sizing problem is solved by cost and benefit analysis considering the reliability improvements. Along with the development of battery technologies and introduction of more stimulus policies, the cost of battery will decrease, which will make the application of MBESS more attractive.

Acknowledgments This work was supported by the National Natural Science Foundation of China (Young Scholar Program 71401017, General Program 51277016), State Key Laboratory of Alternate Electrical Power System with Renewable Energy Sources (Grant No. LAPS14002), Fujian regional science and technology major projects, China (2013H41010151), and Hong Kong RGC Theme Based Research Scheme Grant No. T23-407/13-N.

Open Access This article is distributed under the terms of the Creative Commons Attribution 4.0 International License (http://creativecommons.org/licenses/by/4.0/), which permits unrestricted use, distribution, and reproduction in any medium, provided you give appropriate credit to the original author(s) and the source, provide a link to the Creative Commons license, and indicate if changes were made.

\section{References}

[1] The smart grid: an introduction (2009) Office of Electricity Delivery and Energy Reliability, prepared for the U.S. Department of Energy by Litos Strategic Communication under contract No. DE-AC26-04NT41817, Subtask 560.01.04. Washington, DC, USA

[2] Li FX, Qiao W, Sun HB et al (2010) Smart transmission grid: vision and framework. IEEE Trans Smart Grid 1(2):168-177

[3] Zhang P, Li FX, Bhatt N (2010) Next-generation monitoring, analysis, and control for the future smart control center. IEEE Trans Smart Grid 1(2):186-192

[4] Fujian China Electric Power Research Institute Mobile Energy Storage Station II. DOE Global Energy Storage Database. http:// www.energystorageexchange.org/projects/154. Accessed May 2015

[5] Conti S, Nicolosi R, Rizzo SA (2012) Generalized systematic approach to assess distribution system reliability with renewable distributed generators and microgrids. IEEE Trans Power Deliv 27(1):261-270

[6] Bie ZH, Zheng P, Li GF et al (2012) Reliability evaluation of active distribution systems including microgrids. IEEE Trans Power Syst 27(4):2342-2350

[7] Brown RE, Ochoa JR (1998) Distribution system reliability: default data and model validation. IEEE Trans Power Syst 13(2):704-709

[8] Tsao TF, Chang HC (2003) Composite reliability evaluation model for different types of distribution systems. IEEE Trans Power Syst 18(2):924-930

[9] Billinton R, Acharya JR (2006) Weather-based distribution system reliability evaluation. IEE Proc Gener Transm Distrib 153(5):499-506

[10] Sohn JM, Nam SR, Park JK (2006) Value-based radial distribution system reliability optimization. IEEE Trans Power Syst 21(2):941-947

[11] Al-Muhaini M, Heydt GT (2013) A novel method for evaluating future power distribution system reliability. IEEE Trans Power Syst 28(3):3018-3027

[12] Billinton R, Huang DG (2008) Effects of load forecast uncertainty on bulk electric system reliability evaluation. IEEE Trans Power Syst 23(2):418-425

[13] Hu P, Karki R, Billinton R (2009) Reliability evaluation of generating systems containing wind power and energy storage. IET Gener Transm Distrib 3(8):783-791

[14] Xie KG, Cao K, Yu DC (2011) Reliability evaluation of electrical distribution networks containing multiple overhead feeders on a same tower. IEEE Trans Power Syst 26(4):2518-2524

[15] Chowdhury AA, Koval DO (2009) Power distribution system reliability: practical methods and applications. Wiley, Hoboken

[16] Billinton R, Allan RN (1996) Reliability evaluation of power systems, 2nd edn. Springer, Boston

[17] Hamoud GA (2012) Use of Markov models in assessing spare transformer requirements for distribution stations. IEEE Trans Power Syst 27(2):1098-1105

[18] Billinton R, Wang P (1998) Distribution system reliability cost/worth analysis using analytical and sequential simulation techniques. IEEE Trans Power Syst 13(4):1245-1250

[19] Billinton R, Wang P (1999) Teaching distribution system reliability evaluation using Monte Carlo simulation. IEEE Trans Power Syst 14(2):397-403

[20] Zheng Y, Dong ZY, Luo FJ et al (2014) Optimal allocation of energy storage system for risk mitigation of DISCOs with high renewable penetrations. IEEE Trans Power Syst 29(1):212-220

[21] Zheng Y, Dong ZY, Meng K et al (2013) A control strategy of battery energy storage system and allocation in distribution system. In: Proceedings of the 2013 IEEE power and energy society general meeting, Vancouver, Canada, 21-25 Jul 2013, 5 $\mathrm{pp}$

[22] Heydt GT, Graf TJ (2010) Distribution system reliability evaluation using enhanced samples in a Monte Carlo approach. IEEE Trans Power Syst 25(4):2006-2008

[23] Akorede MF, Hizam H, Aris I et al (2011) Effective method for optimal allocation of distributed generation units in meshed electric power systems. IET Gener Transm Distrib 5(2):276-287

Yu ZHENG is a research assistant of the department of electrical and electronic engineering, The University of Hong Kong. His research interests include power system planning, smart grid, and intelligent system applications to power engineering. 
Zhaoyang DONG is Professor and Head of School of Electrical and Information Engineering, The University of Sydney, Australia. He is also the director for the Faculty of Engineering and IT research cluster on clean intelligent energy networks at the University of Sydney. He is immediate Ausgrid Chair and Director of the Centre for Intelligent Electricity Networks (CIEN), the University of Newcastle, Australia. He previously held academic and industrial positions with the Hong Kong Polytechnic University, and Transend Networks, Australia. His research interests include smart grid, power system planning, power system security, load modeling, renewable energy systems, electricity market, and computational intelligence and its application in power engineering. He is an editor of IEEE Transactions on Smart Grid, IET Renewablw Power Generation, and IEEE PES Letters.

Shilin HUANG is currently President of Ningde Amperex Technology Ltd. His research interests include battery energy storage systems and battery management systems.

Ke MENG is currently with the School of Electrical and Information Engineering, The University of Sydney, Australia. His research interests include pattern recognition, power system stability analysis, wind power, and energy storage.
Fengji LUO is a research associate of the Centre for Intelligent Electricity Networks, The University of Newcastle, Australia. His research interests include computational intelligence applications, distributed computing, and power system operations \& planning.

Jie HUANG is now a researcher in State Grid Electric Power Research Institute (SGEPRI), State Grid Corporation of China. His research interests include electricity market modelling and simulation, risk management, and policy issues related with emission trading.

David HILL currently holds the Chair of Electrical Engineering at the University of Hong Kong. He is also a part-time Professor at The University of Sydney, Australia. His research interests are in control, networks, power systems, and stability analysis. Prof. Hill is a Fellow of IEEE, the Society for Industrial and Applied Mathematics, USA, the Australian Academy of Science, and the Australian Academy of Technological Sciences and Engineering. He is also a Foreign Member of the Royal Swedish Academy of Engineering Sciences. 